ISBN 978-93-84468-92-7

International Conference on Issues in Education, Literature, Humanities and Social Sciences

(IELHSS-2017)

Kuala Lumpur (Malaysia) Jan. 4-5, 2017

\title{
A Comparative Study of Spirituality and Psychological Well- Being among Senior Secondary Male and Female Students
}

\author{
Farzana Parveen ${ }^{1}$, and Shahina Maqbool ${ }^{2}$ \\ ${ }^{1}$ Research Scholar, Department of Psychology, Aligarh Muslim University, Aligarh \\ ${ }^{2}$ Professor, Department Of Psychology, Aligarh Muslim University, Aligarh
}

* Abstract: Now a day's most of the researchers focused on adolescents that are the most crucial and critical stage of their life. In this study we want to know to what extent does spirituality and psychological well-being play a vital role in adolescent's life, and to what extent both are correlated. Objective to examine the relationship between spirituality and psychological well-being among male and female students and to explore the gender difference with respect to spirituality and psychological well-being. The participants of the present study comprised N=100 students which is further divided $n=50$ male and $n=50$ female and they were from senior secondary schools and recruited from Metropolitan cities, their age ranged from 13 to 18 years. Data were collected through Spirituality questionnaire and Psychological well-being questionnaire. Results showed that there was insignificant difference between male and female students on spirituality and significant difference between male and female students on psychological wellbeing. Relationship showed that there was positive correlation between spirituality and psychological well-being. Result was analyzed by SPSS version 20.0 software.

Keywords: Spirituality, Psychological well-being, Males, Females

\section{Introduction}

Adolescence is a complex, multi- system transitional process involving progression from the immaturity and social dependency of childhood into adult life with the goal and expectation of fulfilled developmental potential, personal agency, and social accountability (Greenfield, Keller, Fuligni, \& Maynard, 2003; Graber \& BrookesGunn, 1996; Modell \& Goodman, 1990; Steinberg, 2002).

Spirituality is an additional internal characteristic that have been linked with the Psychological well-being, Spirituality can be considered as a basic human quality that transcends gender, race, color, and national origin. According to Dosseyet al. (2000), spirituality is the essence of who we are and how we are in the world and, like breathing, is essential to our human existence. The concept of spirituality as a protective factor during adolescence is rather new and untested, recent research suggests that spirituality not only helps youth cope with adversity but also promotes their mental health and well-being(e.g.,Cotton, Larkin, Hoopes, Cromer,\& Rosenthal, 2005; Kelley\&Miller, 2007; Wills, Yaeger, \& Sandy, 2003).

Kuhalampi (2010) lists the fallowing central features of spirituality. Which we believe that is more beneficent for adolescent's life, if they fallow them. Meaning the ontological significance of life, making sense of life situations; deriving purpose in existence. Value beliefs and standard that is cherished; having to do with the truth, beauty, worth of a thought, object or behavior; often discussed as 'ultimate values'. Transcendence experience and appreciation of a dimensions beyond the self; expanding self-boundaries. Connecting relationship with self, others, God/higher power, and the environment. Becoming an unfolding of life that demands reflection and experience; including sense of who one is and how one knows. Hope a prospect of confidence and trust towards the future.

Psychological well-being is an important with respect to how we function and adapt and to whether our lives are satisfying and productive. Psychological well-being refers to how people evaluate their lives. Most of the 
researches views upon psychological well being is that "Individuals are in a state of well-being if they have a high degree of satisfaction with themselves, if their mood is good (positive affect), and if they only occasionally experience unpleasant emotions such as sadness, anger, and inhibitions (negative affect)" (Landa, Martos, \& López-Zafra, 2010, p. 783). A heightened level of psychological well-being is often a precursor for positive or good mental health. According to Ryff and Singer (2008), psychological well-being is contingent on six pillars, namelySelf-acceptance: They have a positive self-regard that includes awareness of personnel limitations. Positive relations with others: They have developed and kept warm ties with others. Personal growth: They have dynamic of lifelong learning and of continuous development of their abilities. Purpose in life: They have a sense of direction in life that unifies their efforts and challenges. Environmental mastery: They create a surrounding context so as to satisfy their needs and desire. Autonomy: They have developed a strong sense of individuality and personal freedom. Psychological well-being is not only associated with the greatest psychological satisfaction but it also has an important implications for adolescents and their mental wellness.

\section{Objectives}

* To examine the relationship between spirituality and psychological well-being among male and female students and to explore the gender difference with respect to spirituality and psychological well-being.

\section{Hypothesis:}

1. There will be a significant relationship between spirituality and psychological well-being among adolescents.

2. There will be no significant difference between male and female on spirituality.

3. There will be no significant difference between male and female on psychological well- being.

\section{Methodology}

Sample: The participant of the present study comprises 100 Students of senior secondary metropolitan schools. It includes 50 males and 50 females, their age ranged from 13 to 18 years. All of them are studying in 11 th \& 12 th class.

\section{Research Tools:}

Spirituality Questionnaire: The Spirituality Questionnaire is developed by Hardt and Schultz et al. in (2012). The items of this questionnaire were coded from zero to four. This questionnaire contained 20 items, and each item were to be answered on a five point Likert scale with the categories Not true at all, Hardly true, Don't know, Rather true, Absolutely true. The reliability of this scale is .78 to .97 .

Psychological Well-Being Scale: Psychological Well-Being Scale developed by Bhogle and Prakash (1995) was used. The scale contains 28 items measuring satisfaction in the four areas of life-marriage, peer comparison, social support and health, an internal consistency of 0.84 and split half coefficient of 0.91 , in retest using the same questionnaire after three months 0.72 correlations was observed.

Procedure: 50 male school going students and 50 female school going students having only (11-12 ${ }^{\text {th }}$ class) of age range 13-18 years old, belonging to Metropolitan city New Delhi near Jamia Nagar. First of all the students were approached and a good rapport was established with them and were explained the purpose of this study and how the results of this study would be used. When the questionnaires were distributed to the subject's great care was taken to remove any misconceptions regarding the proposed study. Further subjects were assured of the confidentiality of their responses and were requested to extend their cooperation.

Statistical Analysis: To find out difference between male and female students of senior secondary class on spirituality and psychological well-being, we used t-test and to know the correlation between spirituality and psychological well being, we used Pearson Product Moment Coefficient of Correlation. 


\section{Results}

TABLE I Showing the relationship between Spirituality and Psychological well-being

\begin{tabular}{|lcccc|}
\hline Variables & N & Mean & Std. Deviation & r \\
\hline Spirituality & 100 & 77.97 & 9.253 & $.217^{*}$ \\
Psychological well-being & 100 & 17.04 & 2.778 & \\
\hline
\end{tabular}

*Significant at .05 level

TABLE II Showing Mean, SD \& t Value of Spirituality and Psychological Well-Being

\begin{tabular}{|llccccc|}
\hline Variables & Gender & $\mathrm{N}$ & Mean & Std. Deviation & $\mathrm{t}$ & $\mathrm{p}$ \\
\hline Spirituality & Male & 50 & 76.58 & 10.310 & 1.512 & .134 \\
& Female & 50 & 79.36 & 7.922 & & \\
& & & & & & \\
& Male & 50 & 16.22 & 2.460 & 3.076 & .003 \\
$\begin{array}{l}\text { Psychological } \\
\text { Well-being }\end{array}$ & Female & 50 & 17.86 & 2.857 & & \\
\hline
\end{tabular}

Result \& Discussion: The present study was conducted to examine the relationship between spirituality and psychological well-being on the whole sample and to compare mean scores of senior secondary male and female students on spirituality and psychological well-being. The objective was to find out the relationship between spirituality and psychological well-being. Result in table no-1 Shows the score of spirituality $(\mathrm{N}=100$, Mean=77.97, $\mathrm{SD}=9.25)$ and psychological wellbeing $(\mathrm{N}=100$, mean=17.04, $\mathrm{SD}=2.77)$ among adolescents respectively. The correlation value of spirituality and psychological well-being had found.217 that shows significant correlation at 0.05 levels. Which indicated a significant positive correlation between spirituality and psychological well-being among senior secondary students $\mathrm{r}=.217$; $\mathrm{p}<0.05$. It implies that high level of spirituality was linked with better psychological well-being and vice-versa. In other words, students who had high spiritual orientation are more psychologically healthy as compared to those who have low spiritual interest and commitment. Thus, the result confirms the first hypothesis. The finding is in line with the study of Trankle reported that high levels of religiosity and religious coping were positively correlated with high levels of psychological well-being. It suggests that participants who were reported healthy psychological well-being also indicated a rich religious life. The finding also corresponds with the studies conducted by Pinkard and Heflinger (2006), Wills et al. (2003), Wong et al. (2006), Pinkard and Heflinger (2006) and Wong et al. (2006). Religious or spiritual involvement promotes individuals' well-being by providing them access to social support, a source from which to cultivate social identity, as well as a factor that encourages individuals to avoid negative health behaviors (George, Ellison, and Larson 2002; Greenfield and Marks, Forthcoming(2007). Table no-2 shows differences between mean scores of male students $(\mathrm{M}=76.58 ; \mathrm{SD}=10.31 ;)$ and female students $(\mathrm{M}=79.36 ; \mathrm{SD}=7.92 ;)$ on spirituality and psychological wellbeing. Findings reveled an insignificant differences between male and female students on spirituality $\mathrm{t}=1.512$; p >0.05. Female students had slightly higher score on spirituality than male students. Comparative studies further suggest that Black women had higher levels of subjective religiosity and spirituality than Black men and White men and women. Similar study also found by (Chatters, Levin, \& Taylor, 1992; Levin, Taylor, \& Chatters, 1994; Taylor, Mattis, \& Chatters, 1999). The result of the present study supports the second hypothesis. The finding is consistent with the result obtained by Victor (2013). Another study conducted by Hammermeister, Flint, El-Alayli, Ridnour, and Peterson (2005) regarding undergraduate college students also reported that female students scored higher on 
all three spiritual or religious health measures in comparison to male students. As far as psychological well-being is concerned, significant difference was observed between male and female students $(t=3.076 ; p<0.05)$. Female students scored higher on psychological well-being $(\mathrm{M}=17.86 ; \mathrm{SD}=2.85)$ as compared to their counterparts $(\mathrm{M}=16.22 ; \mathrm{SD}=2.46)$. A study conducted by Dadhania (2015) on mental health and psychological Well-being in adolescence boys and girls supports this finding. Similar result is also obtained by Betton (2004) who reported that significance difference between male and female American college students on psychological well-being. The result does not confirm the second hypothesis.

\section{Conclusion}

In sum, the study provided an insight into the importance of spirituality and psychological well-being in the life of students. Significant positive association between spirituality and psychological well-being lend support to the previous studies that spirituality promotes psychological well-being. Compared to boys, girls have better psychological well-being. Male and female students did not differ with respect to spirituality. It suggests that importance of spiritual awareness has increased with changing time. Today college students have developed a good sense of spiritual interest and active engagement in spiritual quest can help them to explore the meaning and purpose of life.

Moreover belief in God and relationship with Gods others helps to generate strength, positive attitude, confidence and a sense of control (Cotton, Larkin, Hoops, Cromer \& Rosenthal (2005). This not only helps adolescents cope with the challenges of developmental period but also promotes their psychological well-being. Therefore an attempt should be made to nurture among adolescents at family level. Spirituality is the protective factor during adolescents because connectedness with others and part with God, helps to generate strength, positive attitude, confidence and a sense of control. And actively engaged in a spiritual quest can help them to explore the meaning and purpose of life of oneself and others also. It not only helps students to cope with challenges of developmental period of adversity but also promotes their Psychological well-being.

\section{Suggestions:}

- We need to conduct the studies on 'Spirituality' \& 'Psychological well-being for various cross cultural sample.

- The study should be conducted on the much larger sample of adolescents that is likely to increase the reliability of the findings.

- This type of study can be conducted on population of other age group also.

\section{Implications:}

- Spiritual awareness among adolescents can strengthen their well-being and help to overcome their hardship, mental stress.

- Spirituality and psychological well-being enhances self confidence among adolescents.

- By engaging in religious and spiritual practices, adolescents can avoid negative thoughts and can develop positive attitude about self and others that help them to boost their well-being.

\section{Reference}

[1] Betton, A.,C.,(2004). Psychological Well-Being and Spirituality among African American And European American College Students. The Ohio State University.

[2] Chatters, L. M., Levin, J. S., \& Taylor, R. J. (1992). Antecedents and dimensions of religious involvement among older Black adults. Journals of Gerontology, 47, S269-S278

[3] Cotton, S., Larkin, E., Hoopes, A., Cromer, B., \& Rosenthal, S. (2005). The impact of adolescent spirituality on depressive symptoms and health risk behaviors. Journal of Adolescent Health, 36, 529. 
[4] Dadhania,A.,D.,(2015) Mental Health and Psychological Well-being in Adolescence Boys and Girls . International Journal Of Public Mental Health And Neurosciences ISSN No: 2394-4668 (Published Jointly by Azyme Biosciences (P) Ltd., Sarvasumana Association and Subharati Niriksha Foundation)

[5] George, Ellison, and Larson (2002). Explaining the relationships between religious involvement and health. Psychological Inquiry, 13, 190-200.

[6] Graber, J. A., \& Brooks-Gunn, J. (1996). Transitions and turning points: Navigating the passage from childhood through adolescence. Developmental Psychology, 32(4), 768-776.

[7] Greenfield, P. M., Keller, H., Fuligni, A., \& Maynard, A. (2003). Cultural pathways through universal development. Annual Review of Psychology, 54, 461-490.

[8] Greenfield,E., A.,Vaillant,G.,Marks,F.,N.,(2007). Formal Religious Participation and Daily Spiritual Experiences: Separate, but Equal, Linkages with Psychological Well-Being.

[9] Gupta, V., Saini, M.,(2014). Impact of Spirituality over Job Satisfaction: A Concept. International Journal of Advance Research in Computer Science and Management Studies. Volume 2, Issue 9, ISSN: 2327782.

[10] Hammermeister, J., Flint, M., El-Alayli, A., Ridnour, H., \& Peterson, M. (2005). Gender differences in spiritual wellbeing: Are females more spiritually-well than males? American Journal of Health Studies, 20(2), 80-84.

[11] Hussain, A.,(2011).Spirituality and Holistic Health: A Psychological Perspective. Prasad Psycho Corporation, www.prasadpsycho.com.

[12] Karin Victor (2003). Psychological well-being, religiousness, and spirituality in the lives of adolescents from intact and divorced families. Stellenbosch University http://scholar.sun.ac.za

[13] Kelley, B. S., \& Miller, L. (2007). Life satisfaction and spirituality in adolescents. Research in the Social Scientific Study of Religion, 18, 233-261.

[14] Landa, Martos, \& López-Zafra, (2010). Emotional intelligence and personality traits as predictors of psychological wellbeing in Spanish undergraduates. Social Behavior and Personality, 38(6), 783-794.

doi: http://dx.doi.org/10.2224/sbp.2010.38.6.783

[15] Levin, J. S., Taylor, R. J., \& Chatters, L. M. (1994). Race and gender differences in religiosity among older adults: Findings from four national surveys. Journals of Gerontology, 49, S137-S145.

[16] Modell, J., \& Goodman, M. (1990). Historical perspectives. In S. S. Feldman \& G. R. Elliott (Eds.), At the threshold: The developing adolescent (pp. 93-122). Cambridge: Harvard University Press.

[17] Pinkard, T. J., \& Heflinger, C. A. (2006). Religious activity and pastoral counselling among protestant youth with SED. Journal of Child and Family Studies, 15(3), 359-372. doi: 10.1007/s10826-006-9024-2

[18] Ryff and Singer (2008). Know thyself and become what you are: A eudaimonic approach to psychological well-being. Journal of Happiness Studies, 9(1), 13-39.

[19] Steinberg, L. (2002). Adolescence (6th ed.). Boston, MA: McGraw Hill.

[20] Taylor, R. J., Mattis, J., \& Chatters, L. M. (1999). Subjective religiosity among African Americans: A synthesis of findings from five national samples. Journal of Black Psychology, 25, 524-543.

[21] Trankle, M., T., .Psychological Well-Being, Religious Coping, and Religiosity in College Students . Adolescent Religiosity and Psychological Well-Being.

[22] Victor, K., (2013). Psychological well-being, religiousness, and spirituality in the lives of adolescents from intact and divorced families. Stellenbosch University http://scholar.sun.ac.za

[23] Wills, T. A., Yaeger, A. M., \& Sandy, J. M. (2003). Buffering effect of religiosity for adolescent substance use. Psychology of Addictive Behaviors, 17(1), 24-31.

[24] Wills, T. A., Yaeger, A. M., \& Sandy, J. M. (2003). Buffering effects of religiosity for adolescent substance abuse. Psychology of Addictive Behaviours, 17(1), 24-31. doi: 10.1037/0893-164x.17.1.24

[25] Wong, Y. J., Rew, L., \& Slaikeu, K. D. (2006). A systematic review of recent research on adolescent religiosity/spirituality and mental health. Issues in Mental Health Nursing, 27, 161-183. doi: 10.1080/01612840500436941 